\title{
Can spectral-spatial image segmentation be used to discriminate experimental burn wounds?
}

Lukasz A. Paluchowski

Håvard B. Nordgaard

Asgeir Bjorgan

Håkon Hov

Sissel M. Berget

Lise L. Randeberg 


\title{
Can spectral-spatial image segmentation be used to discriminate experimental burn wounds?
}

\author{
Lukasz A. Paluchowski, ${ }^{a}$ Håvard B. Nordgaard, ${ }^{b}$ Asgeir Bjorgan, ${ }^{a}$ Håkon Hov, ${ }^{c, d}$ Sissel M. Berget, ${ }^{c}$ and \\ Lise L. Randeberg ${ }^{\mathrm{a}, \star}$ \\ aNorwegian University of Science and Technology, Faculty of Information Technology, Department of Electronics and Telecommunications, \\ Mathematics and Electrical Engineering, NTNU, Trondheim 7491, Norway \\ ${ }^{\mathrm{b}}$ Trondheim University Hospital, St. Olavs Hospital, Department of Plastic Surgery, Trondheim 7030, Norway \\ 'Trondheim University Hospital, St. Olavs Hospital, Department of Pathology and Medical Genetics, Trondheim 7030, Norway \\ 'Norwegian University of Science and Technology, Faculty of Medicine, NTNU, Department of Laboratory Medicine, Children's and Women's \\ Health, Trondheim 7491, Norway
}

\begin{abstract}
Hyperspectral imaging (HSI) is a noncontact and noninvasive optical modality emerging the field of medical research. The goal of this study was to determine the ability of HSI and image segmentation to discriminate burn wounds in a preclinical porcine model. A heated brass rod was used to introduce burn wounds of graded severity in a pig model and a sequence of hyperspectral data was recorded up to 8-h postinjury. The hyperspectral images were processed by an unsupervised spectral-spatial segmentation algorithm. Segmentation was validated using results from histology. The proposed algorithm was compared to $K$-means segmentation and was found superior. The obtained segmentation maps revealed separated zones within the burn sites, indicating a variation in burn severity. The suggested image-processing scheme allowed mapping dynamic changes of spectral properties within the burn wounds over time. The results of this study indicate that unsupervised spectral-spatial segmentation applied on hyperspectral images can discriminate burn injuries of varying severity. ( ) The Authors. Published by SPIE under a Creative Commons Attribution 3.0 Unported License. Distribution or reproduction of this work in whole or in part requires full attribution of the original publication, including its DOI. [DOI: 10 .1117/1.JBO.21.10.101413]
\end{abstract}

Keywords: hyperspectral imaging; image segmentation; burn wounds.

Paper 150820SSR received Dec. 7, 2015; accepted for publication Apr. 28, 2016; published online May 26, 2016.

\section{Introduction}

Clinical examination of burn severity and prediction of clinical outcome is a complex and difficult task even for an experienced burn surgeon. Although superficial and full-thickness burns are relatively easy to discriminate, a very thin line exists between superficial partial-thickness and deep partial-thickness injuries, primarily due to progressive time-related changes of the burn severity (i.e., burn conversion). ${ }^{1}$ Clinical inspection based on visual and tactile observation is still the most common diagnostic procedure. ${ }^{2,3}$ Recently, a number of optical technologies have been developed and investigated to help clinicians with assessment of burn wound severity. A thorough review of both microscopic and macroscopic optical techniques showing potential in the field of burn wound evaluation has been published by Kaiser et al. ${ }^{4}$ Conventional histologic analysis is still considered the gold standard in evaluation of burn depth, despite the new possibilities that come with a wide range of optical techniques. Histology allows assessment of cellular vitality and tissue degradation. However, the technique has an invasive nature and comes with a significant risk of sampling error due to heterogeneity within the burn area, as only a limited number of biopsies can be collected. As an alternative, several optical modalities have been tested for assessing burn severity, e.g., laser Doppler imaging (LDI), near-infrared spectroscopy, confocal microscopy, laser speckle imaging, spatial frequency domain imaging (SFDI), photoacoustic microscopy, optical

*Address all correspondence to: Lise L. Randeberg, E-mail: lise.randeberg@ ntnu.no coherence tomography, and spectral imaging. Among those modalities, LDI is the most widely recognized and established optical modality for burn assessment. LDI can successively measure changes in microvascular blood flow in the remaining dermis $^{5,6}$ and the generated maps of perfusion can be used to assess burn depth and determine a course of treatment. ${ }^{7,8}$ However, interpretation of the blood flow maps can be difficult and the method itself is sensitive to positioning and patient movement during examination. ${ }^{9}$

Wide-field imaging is another group of optical imaging technologies rapidly emerging in the field of skin tissue characterization. So far, SFDI is one of the most promising modalities. SDFI is able to measure spatially resolved concentration of several clinically relevant chromophores including oxyhemoglobin, deoxyhemoglobin, lipid, water, and tissue oxygenation, as well as changes in the reduced scattering coefficient. These measurements can be performed noninvasively and in vivo. ${ }^{10}$ Animal studies performed on both rat and porcine burn models show a clear distinction between superficial and deep wounds as well as dynamic changes of optical properties caused by the injury. ${ }^{11,12}$

Hyperspectral imaging (HSI) can also be used for measurements and targeting of specific chromophores within skin tissue. The technique provides both spectral and spatial information in one measurement and is a rapidly growing modality for biomedical applications. Several medical applications have emerged during the last years as the technology has become more available, e.g., monitoring tumor hypoxia ${ }^{13}$ and cancer detection using fluorescent techniques. ${ }^{14}$ Advanced hyperspectral microscopic techniques have also been developed. ${ }^{15-17}$ The technology is 
still under development; however, a number of publications report encouraging results. ${ }^{18,19}$ As HSI comprises both spectroscopic measurements and imaging, it enables combination of spectroscopic and statistical image analysis methods. ${ }^{20-22}$ For situations requiring immediate answers, the analysis can be performed in real time. ${ }^{23,24}$ Although a number of spectroscopic methods for evaluation of burn severity have been developed, ${ }^{25-27}$ translation of established algorithms to hyperspectral analysis is not straightforward. Thus, only a small number of publications report the use of HSI for burn characterization. Eisenbeiss et al. ${ }^{28}$ reported image classification of multispectral images for assessment of burn depth. The study yielded promising results, however, the method does not exploit the full spectral information available. Calin et al. ${ }^{29}$ performed spectral classification combined with linear unmixing of hyperspectral data collected from a burn wound. The preliminary results show possibility to generate a fractional abundance map of different tissue types. However, the selection of endmembers was done manually on uncalibrated radiance data, making the method subjective and noise sensitive.

In this study, an unsupervised spectral-spatial segmentation scheme is proposed for analyzing burn wounds. The objective of this study is to exploit all the spectral and spatial information provided by HSI. The method aims at differentiating skin regions within a burn wound and the adjacent healthy skin based on the spectral properties of the injured tissue. Obtained segmentation maps will serve as a foundation for further analysis and estimation of the optical properties of burn wounds.

\section{Materials and Methods}

\subsection{Study Overview}

Two Noroc pigs (hybrid of 1/4 Duroc, 1/4 Yorkshire, and 1/2 Norwegian landrace, weight $30 \mathrm{~kg}$ ) were included in the study. The animals received care in accordance with the "European Convention for the Protection of Vertebrate Animals used for Experimental and Other Scientific Purposes, Strasbourg, 18.III 1986," and Norwegian national regulations. Approval was given by the Norwegian Ethics Committee on animal research. The animals were housed and acclimatized in the animal laboratory for 2 days prior to the experiment. At completion of the experiments, the animals were sacrificed using an intravenous injection of pentobarbital $100 \mathrm{mg} / \mathrm{ml}$.

Six burn locations on the ventral side of the animal were chosen. The burn wounds were introduced using a brass metal rod heated in boiling water. The burn sites were monitored using an HSI system previous to creating the burns, immediate postburn, and at specific times up to $8 \mathrm{~h}$ after the injury ( $30 \mathrm{~h}$ for another animal). Punch biopsies for histological evaluation of burn severity were collected from all the burn sites at the time of euthanasia (8- and 30-h postburn).

The collected hyperspectral images of the burns were used to implement image segmentation algorithm and to determine the ability of HSI technology to differentiate acute thermal injuries. The obtained segmentation maps of burn wounds were compared to $K$-means clustering approach and validated by histology results.

\subsection{Experiments}

The animals received premedication with intramuscular azaperone $4 \mathrm{mg} / \mathrm{kg}$ and diazepam $0.40 \mathrm{mg} / \mathrm{kg}$. An ear vein was cannulated for administration of intravenous anesthesia. General

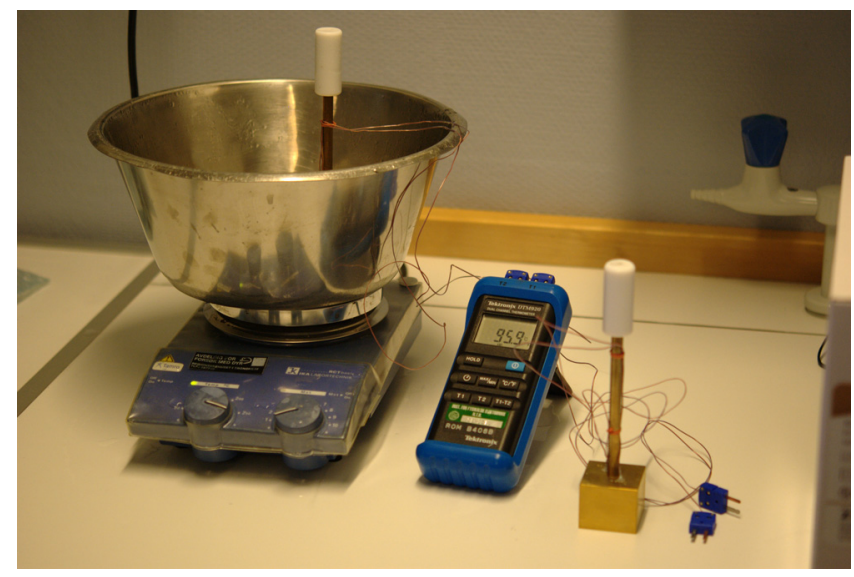

Fig. 1 Brass metal rod during warming up process.

anesthesia was induced with intravenous atropine $0.04 \mathrm{mg} / \mathrm{kg}$, thiopental $10 \mathrm{mg} / \mathrm{ml}$, and ketamine $10 \mathrm{mg} / \mathrm{ml}$. The general anesthesia was maintained by infusions of intravenous fentanyl $0.007 \mathrm{mg} / \mathrm{kg} / \mathrm{h}$. One dose of intravenous antibiotics (2 g cefalotin) was given peroperatively. The animal was ventilated with room air through a tracheotomy tube, and ventilator settings were adjusted according to blood gas measurements. Normovolemia was maintained with Ringer's acetate.

Once the animals were anesthetized and stable, the burn wounds were introduced. The burns were made by a single operator using a heated brass metal $\operatorname{rod}(4 \times 4 \times 3 \mathrm{~cm}, 500 \mathrm{~g})$. The brass rod was immersed in $100^{\circ} \mathrm{C}$ boiling water and the temperature of the rod was monitored using two PFA-insulated thermocouples (OMEGA Engineering, Inc., Stamford, Connecticut) mounted inside the brass block (Fig. 1).

The heated rod was applied to marked skin regions with no other force than gravity for 1, 1.5, 2, 3, 4, and $5 \mathrm{~s}$. By ranging the contact times, it was intended to create burn wounds of different severities. Once all wounds were created, hyperspectral images were acquired immediately postburn (10 $\mathrm{min})$ and every hour up to $8 \mathrm{~h}$ after the burn injury. The burn wounds and surrounding skin were imaged in the same image. Additionally, a diffuse reflectance calibration tile (Spectralon ${ }^{\circledR}$ SRM-99, Labsphere, New Hampshire) was placed close to the burn site to allow conversion to reflectance. There was no direct contact between the imaging system and the animal, thus the potential risk of infection was minimized. The burn spots were visually inspected by a physician specialized in burn treatment and locations for collection of biopsies were identified. Biopsies were collected from the burn and control areas using a 6-mm disposable punch biopsy tool. Each specimen was placed in a separate plastic bottle containing $4 \%$ phosphate-buffered formaldehyde and stored for further histological examination.

\subsection{Hyperspectral Imaging System}

Hyperspectral images were acquired using two push-broom line scanning hyperspectral cameras (HySpex VNIR-1600 and HySpex SWIR-320m-e, Norsk Elektro Optikk AS, Skedsmokorset, Norway). The working spectral range for the VNIR-1600 system is 400 to $1000 \mathrm{~nm}$ with a spectral resolution of $3.7 \mathrm{~nm}$. The size of instantaneous field of view (iFOV) is $\sim 10 \mathrm{~cm}$, with a spatial resolution of 1600 pixels. The SWIR$320 \mathrm{~m}-\mathrm{e}$ system acquires hyperspectral images in the wavelength 
range of 960 to $2500 \mathrm{~nm}$. The size of iFOV is $\sim 9 \mathrm{~cm}$, with a spatial resolution of 320 pixels. The working distance for both cameras was $30 \mathrm{~cm}$. Constant broadband illumination across the iFOV was provided by two fiberoptic lightlines (Illumination Technologies, Inc., New York). Polarizers (VLR-100 NIR, Meadowlark Optics, Frederick, Colorado) were mounted on the camera lens and on the light sources in order to avoid specular reflection from the skin (cross-polarized configuration). Translation stage (Motorized Linear Stage 8MT195, Standa Ltd, Vilnius, Lithuania) and stepper motor (8SMC3-RS232, Standa Ltd, Vilnius, Lithuania) were used to scan the cameras above the burns (Fig. 2). The scanning speed was about $0.5 \mathrm{~cm} / \mathrm{s}$. Calibration parameters of each camera were acquired during a calibration procedure performed prior to the experiment.

\subsection{Histology}

Samples were analyzed using standard $3.5-\mu \mathrm{m}$-thick cuts from paraffin-embedded material stained with hematoxylin and eosin. Three sections from each sample were evaluated in a blinded fashion by two independent pathologists according to the method of Papp et al. ${ }^{30}$ The evaluation was done using a Nikon eclipse Ci microscope (Nikon Gmbh, Düsseldorf, Germany). Measurements of dermal thickness, depth of coagulated collagen, and deepest occluded vessel were performed for all the samples. The burn depth was classified into five anatomical levels: (1) epidermis, (2 to 4) upper, middle, or lower third of dermis, and (5) subcutis. Recollection of morphology to some extent spoiled the blinding between sections in the same sample. In 2 out of 12 samples, the burn depth differed between the two pathologists. These samples were reanalyzed in a two-headed microscope to make a final conclusion. Microscopic images were taken with a Lumenera Infinity 2 camera and Infinity analyze software, release 6.2 (Lumenera Corporation, Ottawa, Ontario, Canada).

\subsection{Image Processing}

In this study, data from the VNIR-camera are presented. The data were converted to radiance by radiometric calibration. This step was followed by a denoising procedure using the minimum noise fraction transformation. ${ }^{31}$ Denoised radiance data were then converted to reflectance according to Eq. (1). This procedure removes the light source component from the spectra,

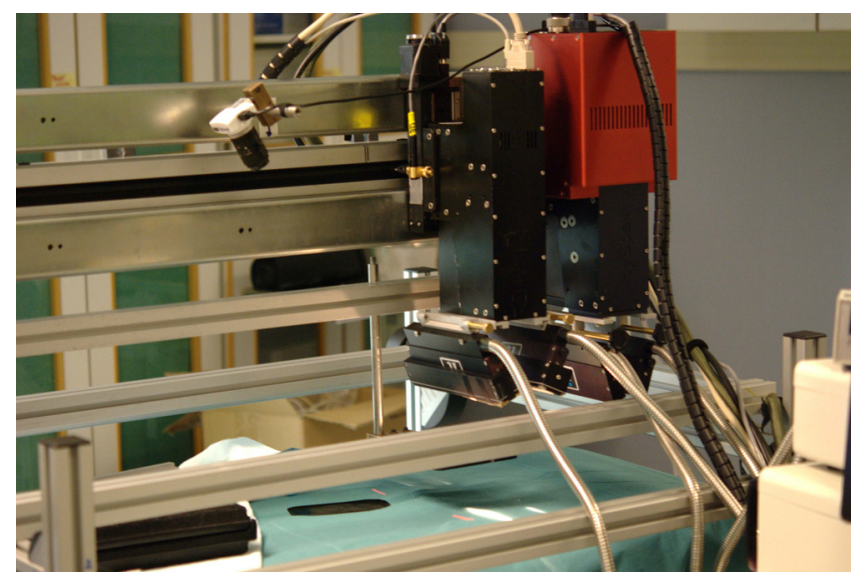

Fig. 2 HSI setup used during the experiment. ensuring that the spectra represent only the amount of light reflected from the skin tissue

$I_{i}=\frac{R_{i} * \operatorname{Iref}_{i}}{W_{i}}$,

where $I$ is reflectance image, $R$ is noise-reduced hyperspectral image, Iref is the known reflectance of the Spectralon calibration tile, $W$ is the noise-reduced hyperspectral image of the Spectralon calibration tile, and $i$ is the band number $i=1,2,3, \ldots, n$, where $n$ is the total number of bands.

To investigate the hyperspectral data from the burn wounds, a spectral-spatial segmentation scheme was implemented. The working principle behind segmentation algorithms differs from classification procedures, where the pixels are assigned to a known class. ${ }^{32}$ In this study, the clusters obtained from segmentation represent skin regions of similar spectral properties. The level of the injury for particular clusters was evaluated using histology results.

The segmentation algorithm is based on assessing spatial dependencies between the pixel of interest and adaptive, spectrally homogeneous neighborhoods. The initial cluster is seeded at the first pixel from the first image line. The algorithm extracts a $3 \times 3$ pixels neighborhood for each pixel of interest. The spectrum of the pixel of interest is compared to the mean spectrum of each cluster existing within the neighborhood. In the first line, there will always be only one cluster within each neighborhood. Once the classification criteria are met, the pixel is assigned to a matching cluster and the mean spectrum of that cluster is updated (Fig. 3). If the classification criteria are not met, a new cluster is established. The decision whether the pixel should be assigned to particular cluster is based on a spectral similarity measure-spectral angle mapper (SAM). SAM is a similarity measure that operates in $n$-dimensional space. The method determines spectral similarity as an angle between two spectra, treating them as vectors in space with dimensionality equal to the number of spectral bands. This method is insensitive to shadowing effects and illumination as the SAM algorithm uses only the vector direction and not the vector length. ${ }^{33}$ After all pixels have been clustered, the algorithm combines nonadjacent
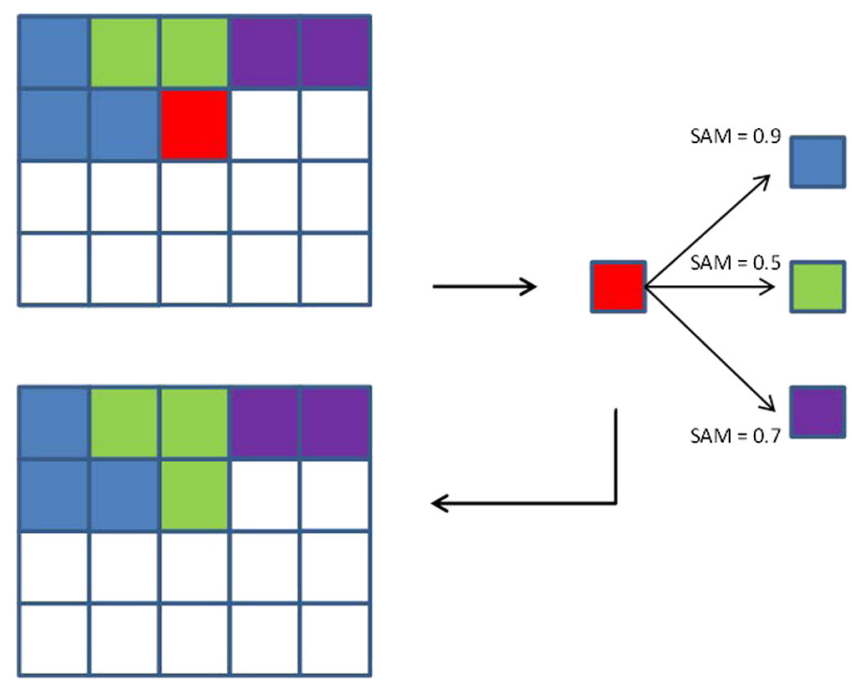

Fig. 3 Spectral-spatial segmentation scheme. The red color represents the pixel to be assign to the matching cluster based on SAM similarity measure. 
clusters that represent regions with similar spectral properties. In the last step, a median filter is used to remove single pixels from the segmentation map.

The number of classes is set as a free parameter. However, the amount of generated classes is related to the similarity threshold used for classification. The threshold used for SAM $(\mathrm{SAM}=1.4)$ was defined based on previous calculations of spectral variation of healthy skin. This approach suggests that skin unaffected by the burn injury should be classified as a single cluster. This threshold is considered as the highest threshold that prevents underestimation of classification results. Setting a lower threshold will lead to overestimation of the classification results and generation of too many clusters. From the image processing point of view, both overestimation and underestimation should be avoided. In the case of skin characterization underestimation is not wanted. This can lead to creating clusters that contain, e.g., a mixture of spectra from surrounding skin and less severe wound regions. Overestimation of the classification results can, to some extent, be accepted. The generated classification map would then contain more classes with lower spectral variability. Thus, the classification map would represent more detailed characterization of wound and skin regions.

The obtained segmentation maps were compared to the correlation driven $K$-means segmentation approach. $K$-means clustering is the most-used clustering algorithm for finding clusters in a set of unlabeled data. ${ }^{34}$ It is an iterative approach that partitions data in $K$-number of predefined clusters. The use of correlation as a metric for $K$-means analysis allows a fair comparison between $K$-means and proposed spectral-spatial classification driven by spectral similarity measure (SAM). Since the number of clusters is fixed, the $K$-means approach is considered as hard partitioning. Thus, proper selection of $K$-number is crucial for correct segmentation. In this study, the $K$-number was always set to match the number of clusters obtained from spectral-spatial segmentation. This allowed for direct comparison of the obtained segmentation maps. Finally, the segmentation maps were compared to histology results in order to check whether the clustering approaches can discriminate skin regions with different types of injury.

\section{Results and Discussion}

To show the principle of the classification method, data from one animal are presented. The complete data set will be used for future estimation of optical properties over a course of $30 \mathrm{~h}$.

\subsection{Histology Evaluation}

In total 12 specimens were examined from a total of six burn sites. One specimen from a control site was included. Out of 12 samples, two were graded as level 1 , four as level 2, three as level 3, two as level 4, and one as level 5. The locations of all biopsy sites are shown in Fig. 4. The histology of the control sample was normal and showed no signs of thermal injury [Fig. 5(a)]. The level 1 burns had occluded vessels only in the uppermost layer of the dermis (papillary dermis). The rest of the upper one-third of the dermis had patent vessels and no collagen damage. The level 2 injuries had both occluded and patent vessels in the upper one-third of the dermis. The collagen damage was visible in the uppermost part of one of the level 2 injuries. The level 3 wounds had patent vessels in the upper one-third of the dermis. The deepest occluded vessels were found in the middle one-third of the dermis. Collagen damage was restricted to the upper one-third of the dermis. The level 4 wounds had

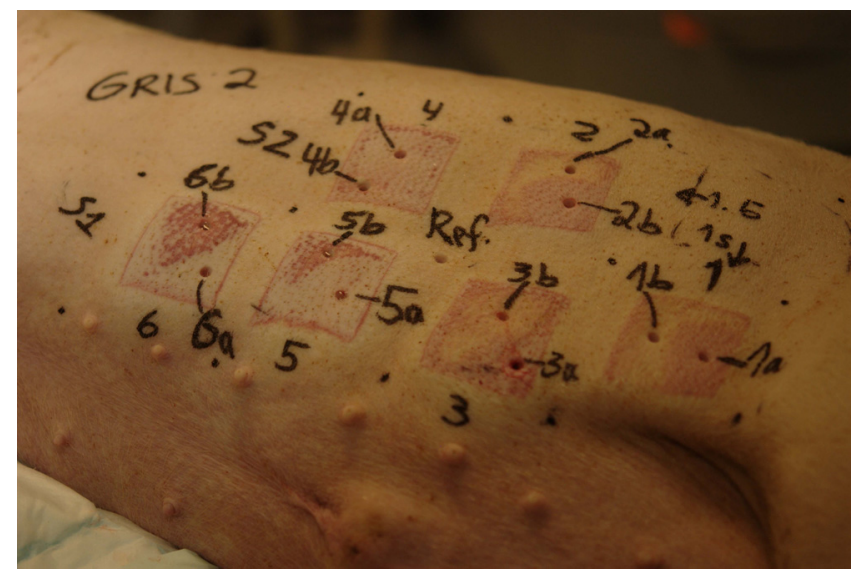

Fig. 4 Location of biopsy sites.

occluded vessels spanning from the middle to the lowest one-third of the dermis. The highest patent vessels were found in upper one-third of the dermis. Injury to the collagen was detected in the upper one-third of the dermis. The level 5 burn [Fig. 5(f)] showed occluded vessels in subcutaneous tissue and collagen injury in the middle one-third of the dermis. Epidermal damage and subepidermal blistering were observed for all burns. Quantitative overview of all biopsy samples is presented in Table 1.

Coagulation of collagen and depth of occluded vessels progressed as the brass rod contact time increased (Fig. 5). There were visible variations of the level of injury within each burn site. These differences are suspected to be caused by adherence of vapor bubbles underneath the brass block. The water vapor accumulated between the brass rod and the skin surface thus affected the heat transfer between the rod and the skin introducing spatial heterogeneity. A similar effect was observed and described by Gaines et al. ${ }^{35}$ However, this is not considered as disadvantage for this study as varying burn severity is common in clinical scenario. Spatial heterogeneity is also advantageous for testing the segmentation algorithm.

\subsection{Image Segmentation}

The proposed spectral-spatial segmentation algorithm was tested on six hyperspectral images of different burn wounds collected at $8 \mathrm{~h}$ postinjury time. Each of the hyperspectral images consisted of a burn wound of varying severity and surrounding healthy skin. The images were stitched together into three groups, each group consisting of two burn wounds from a similar part of the animal. This was done in order to check whether burns of the same severity from different burn wounds can be classified as the same class. Visible local shadows were caused by skin curvature and uneven illumination due to breathing. The obtained segmentation maps were compared to results from $K$-means segmentation and validated by histological evaluation. The burn wounds included in this study are characterized by high heterogeneity. The evaluation of biopsy material confirmed varying severity of the wounds; however, the number of possible categories within each wound remains unknown, primarily due to biopsy sampling. The biopsy samples represent the most critical regions within the wounds that should be delineated using the image classification algorithm.

The segmentation results for all investigated burn sites are shown in Figs. 6-8. The surrounding skin was separated and 


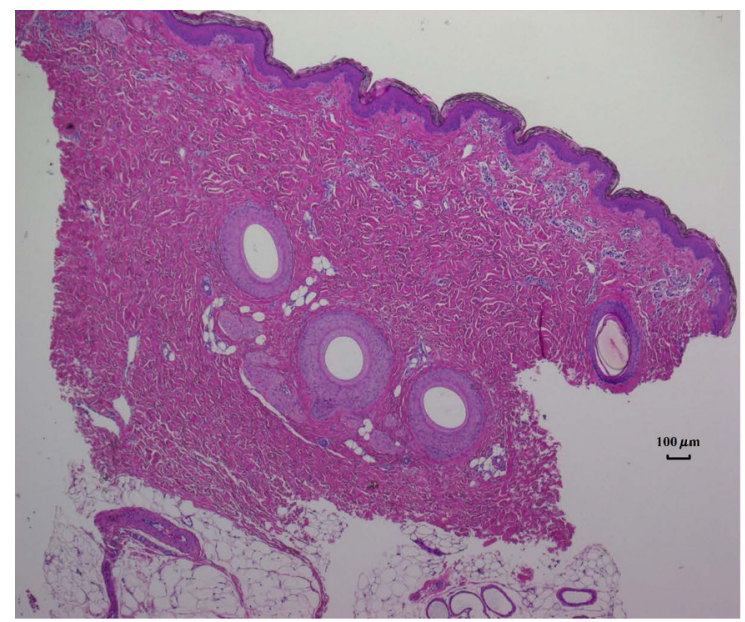

(a)

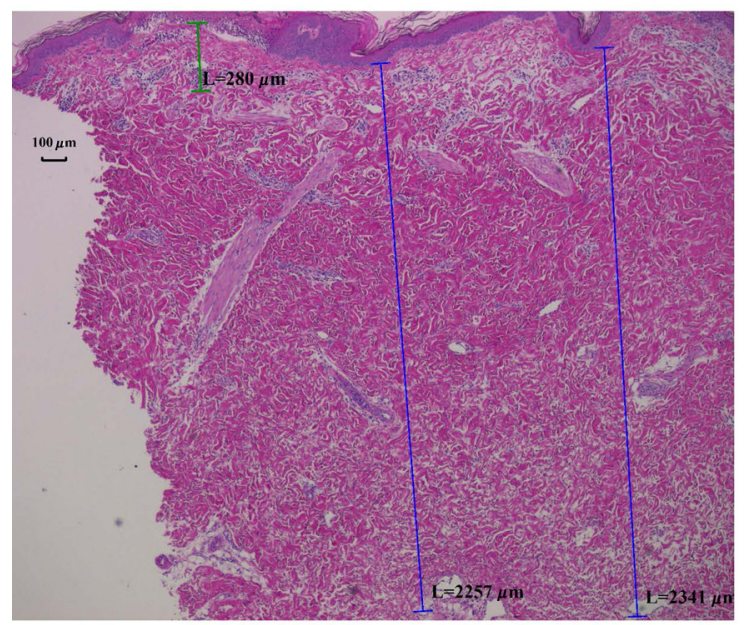

(c)

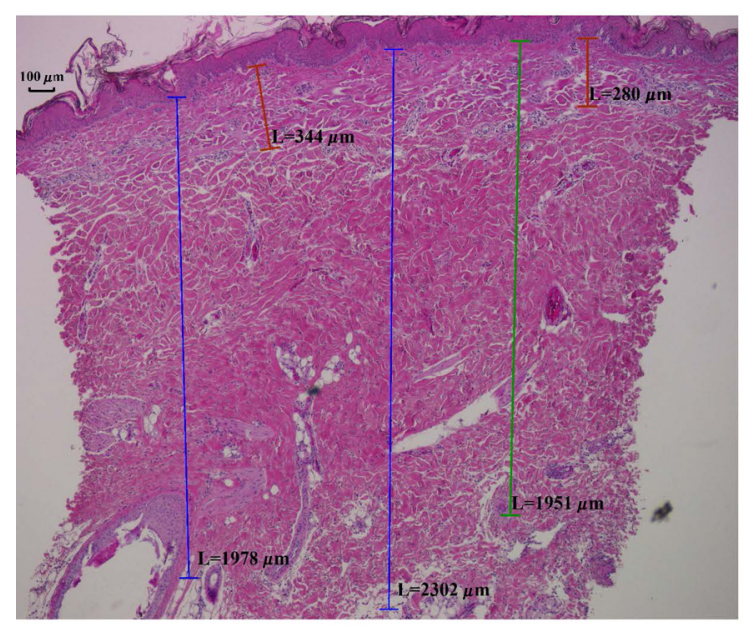

(e)

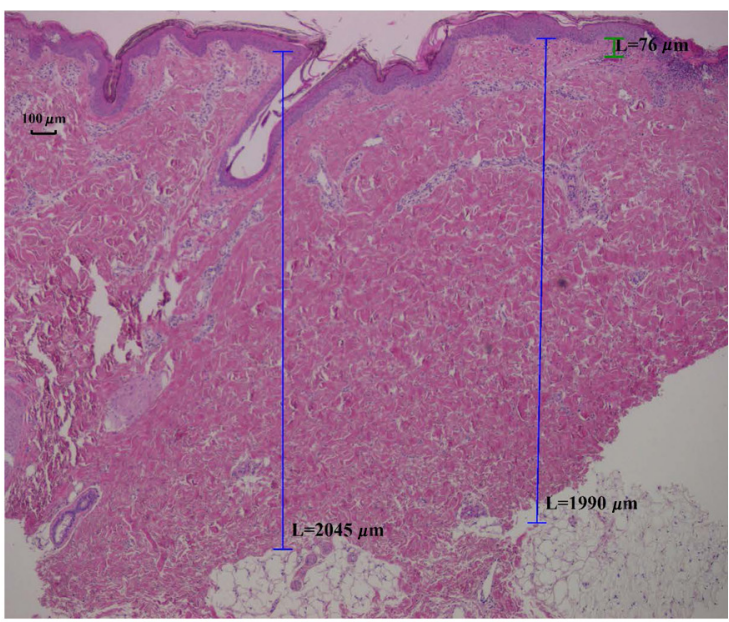

(b)

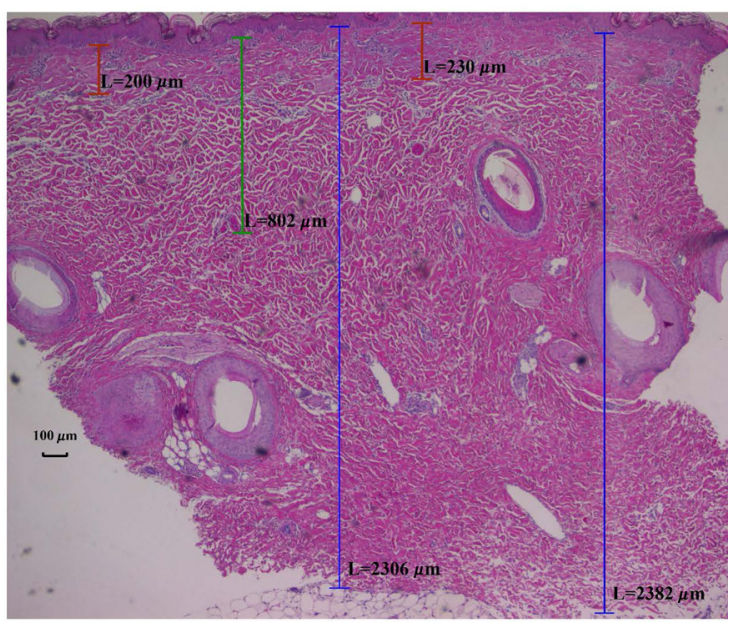

(d)

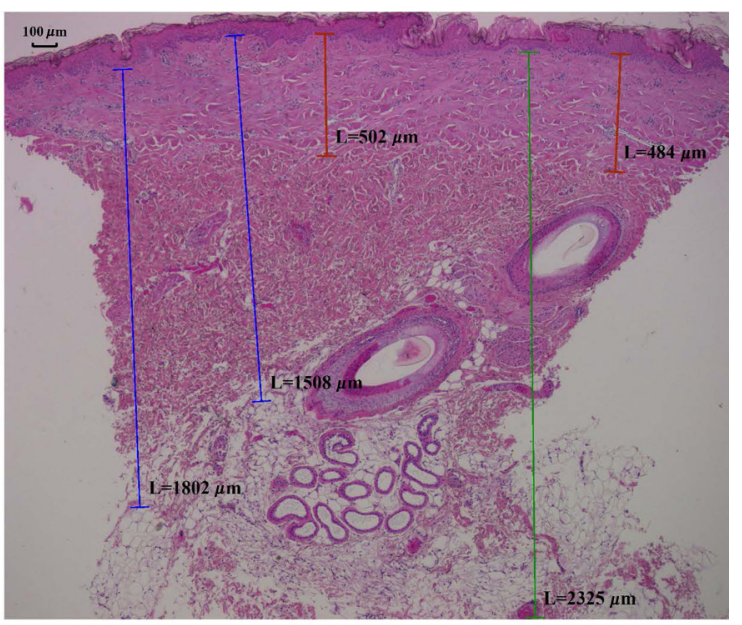

(f)

Fig. 5 Histological evaluation of burn wounds: (a) control site, (b) level 1, (c) level 2, (d) level 3, (e) level 4, and (f) level 5. Red—depth of collagen denaturation, green—deepest occluded vessel, and blue-dermal thickness.

the burn sites are clearly delineated. Local shadows did not affect the segmentation process and the algorithm successfully recognized the skin regions with and without shadow and combined them into one cluster. The skin surrounding the burn injuries was classified into several clusters localized around each burn wound. This indicates that the proposed spectral-spatial classification can recognize spectrally similar skin regions from different locations (Fig. 6). Some oversegmentation of skin regions can be seen in Figs. 7 and 8. This is primary due to the SAM threshold that cannot account for all variation 
Table 1 Histological evaluation.

\begin{tabular}{|c|c|c|c|c|c|c|c|c|c|c|c|c|}
\hline $\begin{array}{l}\text { Sample } \\
\mathrm{nr}\end{array}$ & Round & $\begin{array}{l}\text { Epidermal } \\
\text { damage }\end{array}$ & $\begin{array}{l}\text { Subepidermal } \\
\text { vesicle }\end{array}$ & $\begin{array}{l}\text { Occluded } \\
\text { vessels }\end{array}$ & $\begin{array}{c}\text { Deepest } \\
\text { occluded } \\
\text { vessel } \\
(\mu \mathrm{m})\end{array}$ & $\begin{array}{c}\text { Patent } \\
\text { vessels }\end{array}$ & $\begin{array}{l}\text { Collagen } \\
\text { damage }\end{array}$ & $\begin{array}{c}\text { Collagen } \\
\text { damage } \\
(\mu \mathrm{m})\end{array}$ & $\begin{array}{c}\text { Dermal } \\
\text { thickness } \\
(\mu \mathrm{m})^{\mathrm{a}}\end{array}$ & Level & $\begin{array}{c}\text { Final } \\
\text { decision }\end{array}$ & $\begin{array}{l}\text { Contact } \\
\text { time } \\
\text { (s) }\end{array}$ \\
\hline $2-1 a$ & $\begin{array}{l}1 \\
2\end{array}$ & $\begin{array}{l}\text { Yes } \\
\text { Yes }\end{array}$ & $\begin{array}{l}\text { Yes } \\
\text { Yes }\end{array}$ & $\begin{array}{l}\text { Upper } 1 / 3 \\
\text { Upper } 1 / 3\end{array}$ & 571 & $\begin{array}{l}\text { Upper } 1 / 3 \\
\text { Upper } 1 / 3\end{array}$ & $\begin{array}{l}\text { Upper } 1 / 3 \\
\text { Upper } 1 / 3\end{array}$ & - & 2432 & $\begin{array}{l}2 \\
2\end{array}$ & 2 & 1 \\
\hline $2-1 b$ & $\begin{array}{l}1 \\
2\end{array}$ & $\begin{array}{l}\text { Yes (f) } \\
\text { Yes (f) }\end{array}$ & $\begin{array}{l}\text { Yes (f) } \\
\text { Yes (f) }\end{array}$ & $\begin{array}{l}\text { Upper } 1 / 3(p) \\
\text { Upper } 1 / 3(p, f)\end{array}$ & 76 & $\begin{array}{l}\text { Upper } 1 / 3 \\
\text { Upper } 1 / 3\end{array}$ & $\begin{array}{l}\text { No } \\
\text { No }\end{array}$ & - & 2018 & $\begin{array}{l}1(-2) \\
1(-2)\end{array}$ & 1 & 1 \\
\hline $2-2 a$ & $\begin{array}{l}1 \\
2\end{array}$ & $\begin{array}{l}\text { Yes (f) } \\
\text { Yes (f) }\end{array}$ & $\begin{array}{l}\text { No } \\
\text { Yes (f) }\end{array}$ & $\begin{array}{l}\text { Upper } 1 / 3(p) \\
\text { Upper } 1 / 3(p, f)\end{array}$ & 38 & $\begin{array}{l}\text { Upper } 1 / 3 \\
\text { Upper } 1 / 3\end{array}$ & $\begin{array}{l}\text { No } \\
\text { No }\end{array}$ & - & 2080 & $\begin{array}{l}1(-2) \\
1(-2)\end{array}$ & 1 & 1.5 \\
\hline $2-2 b$ & $\begin{array}{l}1 \\
2\end{array}$ & $\begin{array}{l}\text { Yes } \\
\text { Yes }\end{array}$ & $\begin{array}{l}\text { Yes } \\
\text { Yes }\end{array}$ & $\begin{array}{l}\text { Middle } 1 / 3 \\
\text { Middle } 1 / 3\end{array}$ & 1033 & $\begin{array}{l}\text { Upper } 1 / 3 \\
\text { Upper } 1 / 3\end{array}$ & $\begin{array}{l}\text { Upper } 1 / 3 \\
\text { Upper } 1 / 3\end{array}$ & - & 1982 & $\begin{array}{l}3 \\
3\end{array}$ & 3 & 1.5 \\
\hline $2-3 a$ & $\begin{array}{l}1 \\
2\end{array}$ & $\begin{array}{l}\text { Yes } \\
\text { Yes }\end{array}$ & $\begin{array}{l}\text { Yes } \\
\text { Yes }\end{array}$ & $\begin{array}{c}\text { Middle } 1 / 3 \\
\text { Middle-lower } \\
1 / 3\end{array}$ & 1585 & Upper $1 / 3$ & $\begin{array}{l}\text { Upper } 1 / 3 \\
\text { Upper } 1 / 3\end{array}$ & $<177$ & 2113 & $\begin{array}{l}4 \\
4\end{array}$ & 4 & 2 \\
\hline $2-3 b$ & $\begin{array}{l}1 \\
2\end{array}$ & $\begin{array}{l}\text { Yes (f) } \\
\text { Yes (f) }\end{array}$ & $\begin{array}{l}\text { Yes (f) } \\
\text { Yes (f) }\end{array}$ & $\begin{array}{l}\text { Upper } 1 / 3 \text { (f) } \\
\text { (f) }\end{array}$ & 280 & $\begin{array}{l}\text { Upper } 1 / 3 \\
\text { Upper } 1 / 3\end{array}$ & $\begin{array}{l}\text { No } \\
\text { No }\end{array}$ & - & 2299 & $\begin{array}{l}(1-) 2 \\
(1-)^{2}\end{array}$ & 2 & 2 \\
\hline $2-4 a$ & $\begin{array}{l}1 \\
2\end{array}$ & $\begin{array}{l}\text { Yes } \\
\text { Yes }\end{array}$ & $\begin{array}{l}\text { Yes } \\
\text { Yes }\end{array}$ & $\begin{array}{l}\text { Middle } 1 / 3(f) \\
\text { Middle } 1 / 3\end{array}$ & 802 & $\begin{array}{l}\text { Upper } 1 / 3 \\
\text { Upper } 1 / 3\end{array}$ & $\begin{array}{l}\text { Upper } 1 / 3 \\
\text { Upper } 1 / 3\end{array}$ & $<230$ & 2344 & $\begin{array}{c}(2-) 3 \\
3\end{array}$ & 3 & 3 \\
\hline $2-4 b$ & $\begin{array}{l}1 \\
2\end{array}$ & $\begin{array}{l}\text { Yes } \\
\text { Yes (f) }\end{array}$ & $\begin{array}{l}\text { Yes } \\
\text { No }\end{array}$ & $\begin{array}{l}\text { Upper } 1 / 3 \\
\text { (f) }\end{array}$ & 123 & $\begin{array}{l}\text { Upper } 1 / 3 \\
\text { Upper } 1 / 3\end{array}$ & $\begin{array}{l}\text { No } \\
\text { No }\end{array}$ & - & 1885 & $\begin{array}{c}2 \\
(1-) 2\end{array}$ & 2 & 3 \\
\hline $2-5 a$ & $\begin{array}{l}1 \\
2\end{array}$ & $\begin{array}{l}\text { Yes } \\
\text { Yes }\end{array}$ & $\begin{array}{l}\text { Yes } \\
\text { Yes }\end{array}$ & $\begin{array}{l}\text { Lower } 1 / 3 \\
\text { Lower } 1 / 3\end{array}$ & 1951 & $\begin{array}{l}\text { Upper } 1 / 3 \\
\text { Upper } 1 / 3\end{array}$ & $\begin{array}{l}\text { Upper } 1 / 3 \\
\text { Upper } 1 / 3\end{array}$ & $<344$ & 2140 & $\begin{array}{l}4 \\
4\end{array}$ & 4 & 4 \\
\hline $2-5 b$ & 1 & Yes & Yes & $\begin{array}{c}\text { Upper-middle } \\
1 / 3 \\
\text { Upper } 1 / 3\end{array}$ & 551 & Upper $1 / 3$ & $\begin{array}{l}\text { No } \\
\text { No }\end{array}$ & - & 1936 & $\begin{array}{l}2 \\
2\end{array}$ & 2 & 4 \\
\hline $2-6 a$ & $\begin{array}{l}1 \\
2\end{array}$ & $\begin{array}{l}\text { Yes } \\
\text { Yes }\end{array}$ & $\begin{array}{l}\text { Yes } \\
\text { No }\end{array}$ & $\begin{array}{l}\text { Subcutis } \\
\text { Subcutis }\end{array}$ & 2325 & Middle 1/3 & $\begin{array}{l}\text { Middle } 1 / 3 \\
\text { Middle } 1 / 3\end{array}$ & $<502$ & 1655 & $\begin{array}{l}5 \\
5\end{array}$ & 5 & 5 \\
\hline $2-6 b$ & $\begin{array}{l}1 \\
2\end{array}$ & $\begin{array}{l}\text { Yes } \\
\text { Yes }\end{array}$ & $\begin{array}{l}\text { Yes } \\
\text { Yes }\end{array}$ & $\begin{array}{c}\text { Middle } 1 / 3(f) \\
\text { Upper-middle } \\
1 / 3\end{array}$ & 930 & $\begin{array}{l}\text { Upper } 1 / 3 \\
\text { Upper } 1 / 3\end{array}$ & $\begin{array}{l}\text { Upper } 1 / 3 \\
\text { Upper } 1 / 3\end{array}$ & $<129$ & 2133 & $\begin{array}{l}(2-) 3 \\
2(-3)\end{array}$ & 3 & 5 \\
\hline
\end{tabular}

Note: $p$, papillary dermis; f, focal.

${ }^{a}$ Average depth from two measurement points.

of the skin spectra from normal skin. Increasing the SAM threshold would improve the classification of surrounding skin, but it would also lead to underestimation of the number of classes for the burn wounds. The segmentation maps revealed well-separated zones within the burn sites, indicating a variation in burn severity, as confirmed by the histological evaluation.

However, the burn wounds characterized by the same level of injury (e.g., level 3 in Fig. 6 or level 2 in Fig. 7) were not clustered into the same category as in the case of the surrounding skin. These results indicate differences in local response to the injury. The burn wounds of different severities are in close proximity to one another. Thus interference between the injuries might alter the optical properties of the particular burn wounds, having a direct impact on collected reflectance spectra and generated classification maps. As can be seen in Fig. 8, both levels 4 and 5 wounds have been classified as the same category. According to the histology evaluation (Table 1), the upper parts of the dermis were affected in similar manner for these burns. The differences between collagen coagulation and occluded vessels for those two injuries were observed from the middle part of the dermis down to subcutis ( $~ 850$ to $2500 \mu \mathrm{m}$ ). The total mean penetration depth through a human skin model was estimated to be $\sim 200$ to $800 \mu \mathrm{m}$ for the wavelength range used in this study (400 to $1000 \mathrm{~nm}$ ). This is in accordance with results found for individual skin layers by Svaasand et al. ${ }^{36}$ Tissue structures localized beneath the mean penetration depth are not expected to make a significant contribution to the collected reflectance. Levels 4 and 5 are thus expected to be spectrally similar and classified as the same category.

Variation in burn severity is also indicated by the correlationdriven $K$-means algorithm. However, the interpretation of the segmentation maps is more difficult. The surrounding skin was segmented into many (vertically oriented) clusters, which coincide with known variation in the illumination of the scene. The effect of illumination variation is clearly visible in the RGB images of the burns. The generated clusters are disjoint and the borders are not clearly defined as compared to spectralspatial algorithms. The $K$-means classification maps appear overclassified and suggest very high heterogeneity of the burn wounds. 


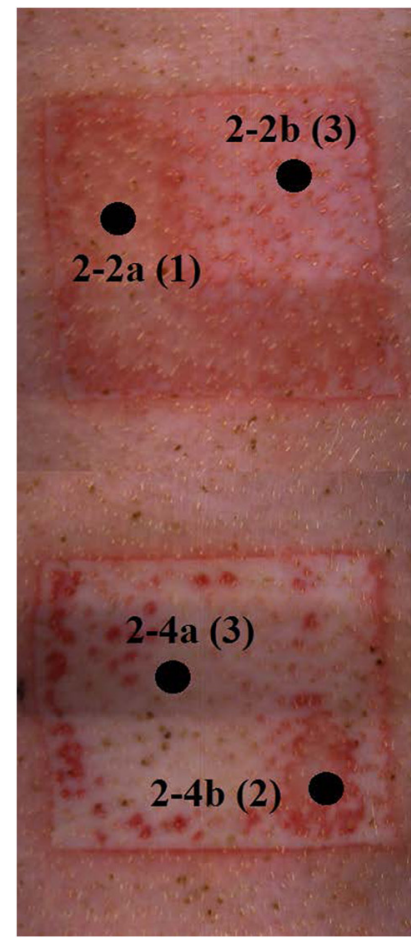

(a)

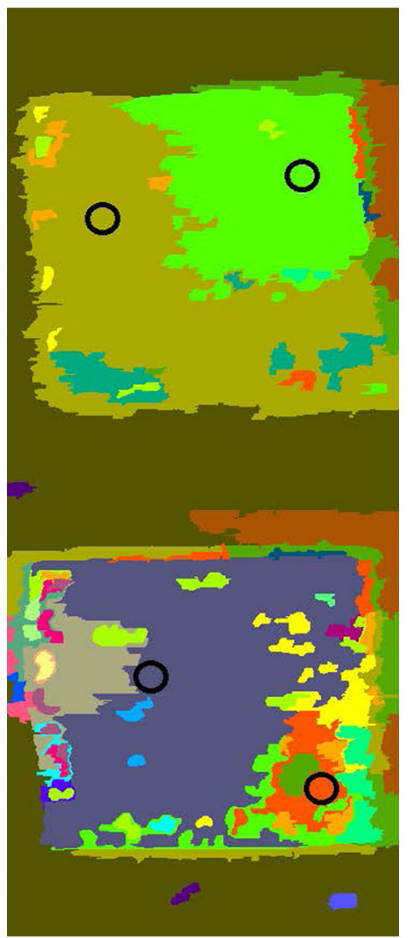

(b)

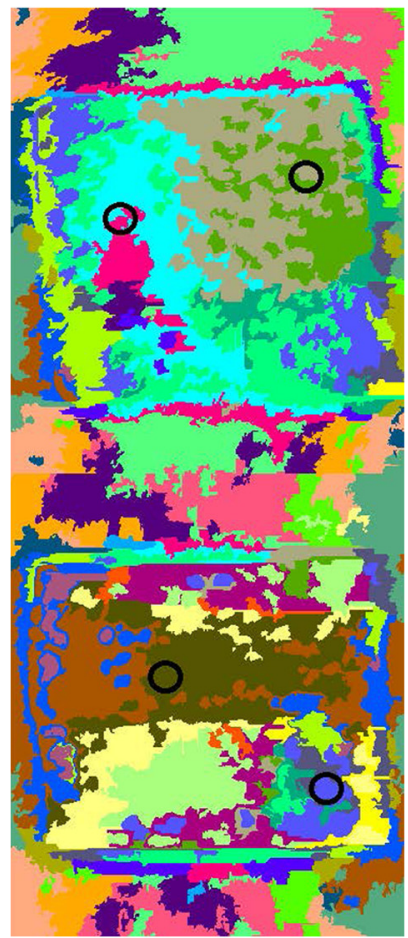

(c)

Fig. 6 Segmentation results of stitched images. (a) RGB image of the burn site, (b) spectral-spatial segmentation map, and (c) $K$-means segmentation map. Biopsy location is marked with circles. The number in brackets describes the burn level.

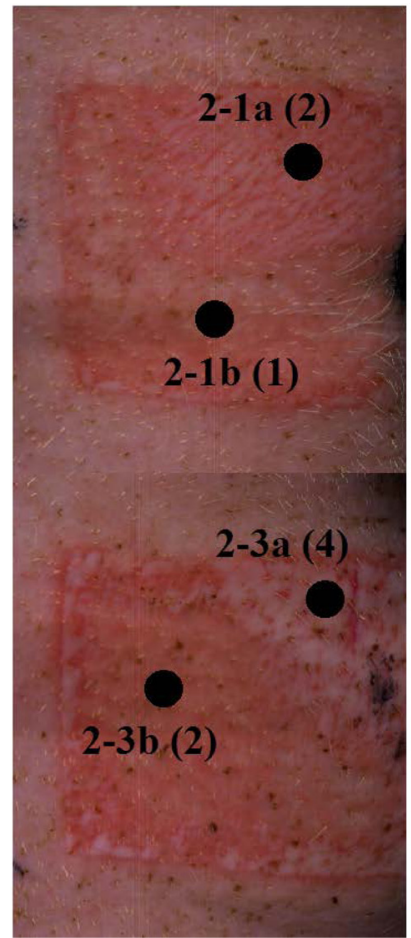

(a)

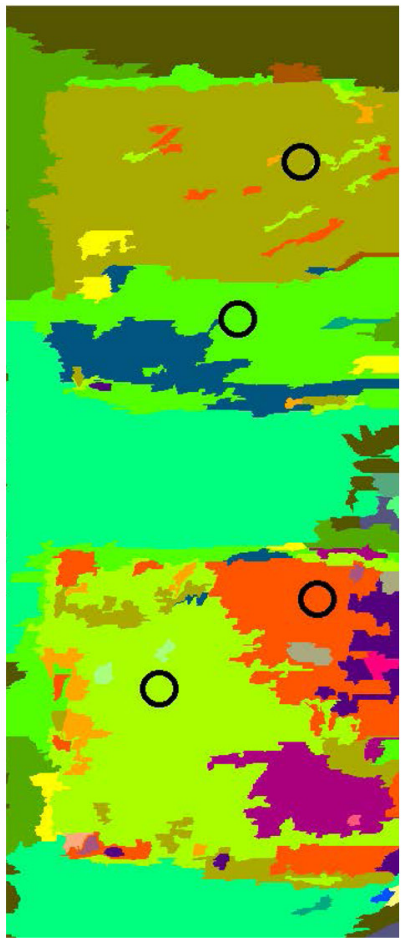

(b)

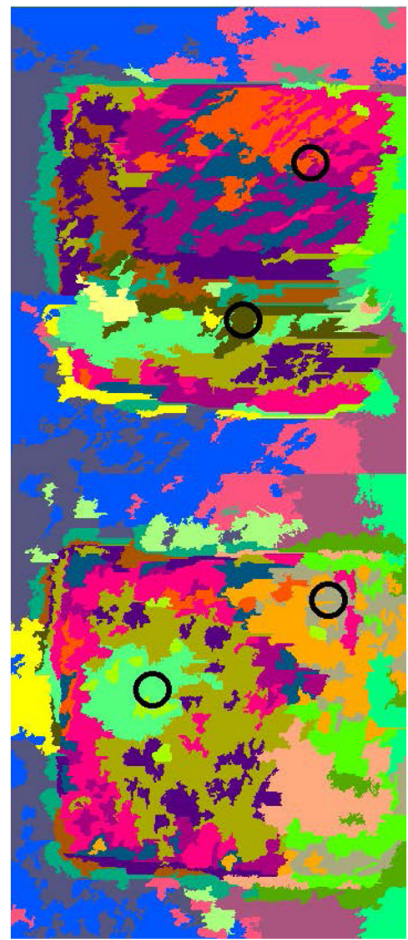

(c)

Fig. 7 Segmentation results of stitched images. (a) RGB image of the burn site, (b) spectral-spatial segmentation map, and (c) $K$-means segmentation map. Biopsy location is marked with circles. The number in brackets describes the burn level. 


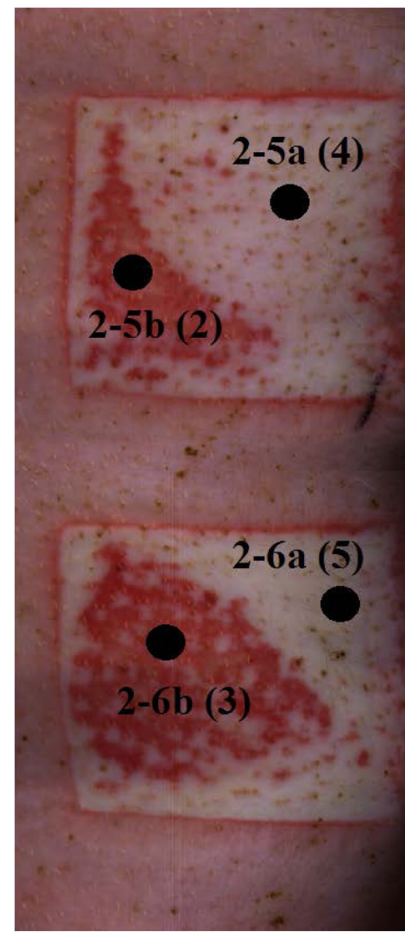

(a)

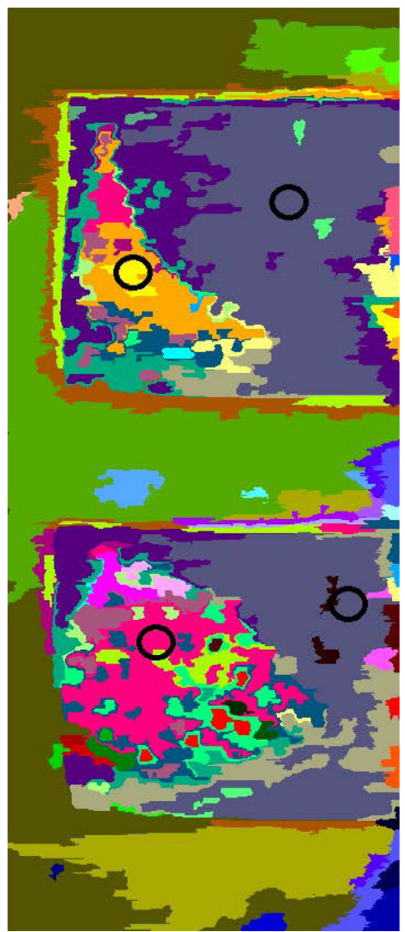

(b)

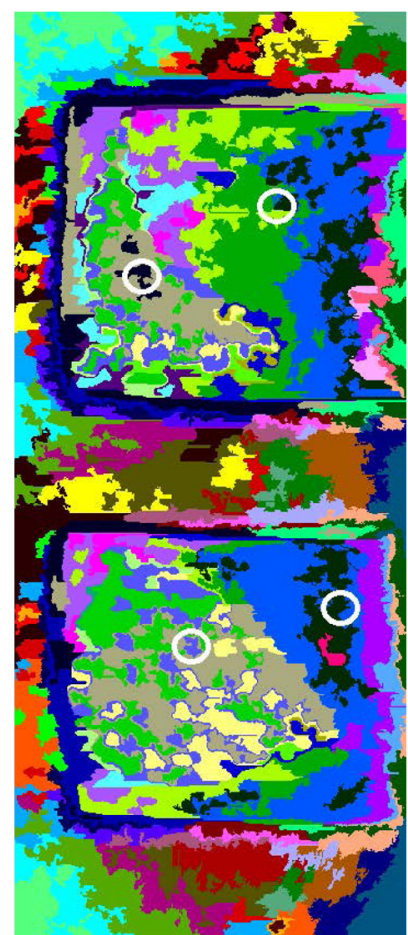

(c)

Fig. 8 Segmentation results of stitched images. (a) RGB image of the burn site, (b) spectral-spatial segmentation map, and (c) $K$-means segmentation map. Biopsy location is marked with circles. The number in brackets describes the burn level.

Taking into account the fact that the proposed segmentation scheme is illumination insensitive and the generated maps reveal the spatial differences within the burn wounds, the spectral-spatial segmentation is considered as well suited for clustering unlabeled hyperspectral images of thermal injuries. Another advantage of the proposed method is that there is no need for the whole image in order to perform segmentation. The algorithm iterates across the image line-by-line, and thus it can be executed in real time for line-scanning hyperspectral devices. Future work will be focused on combining the proposed method
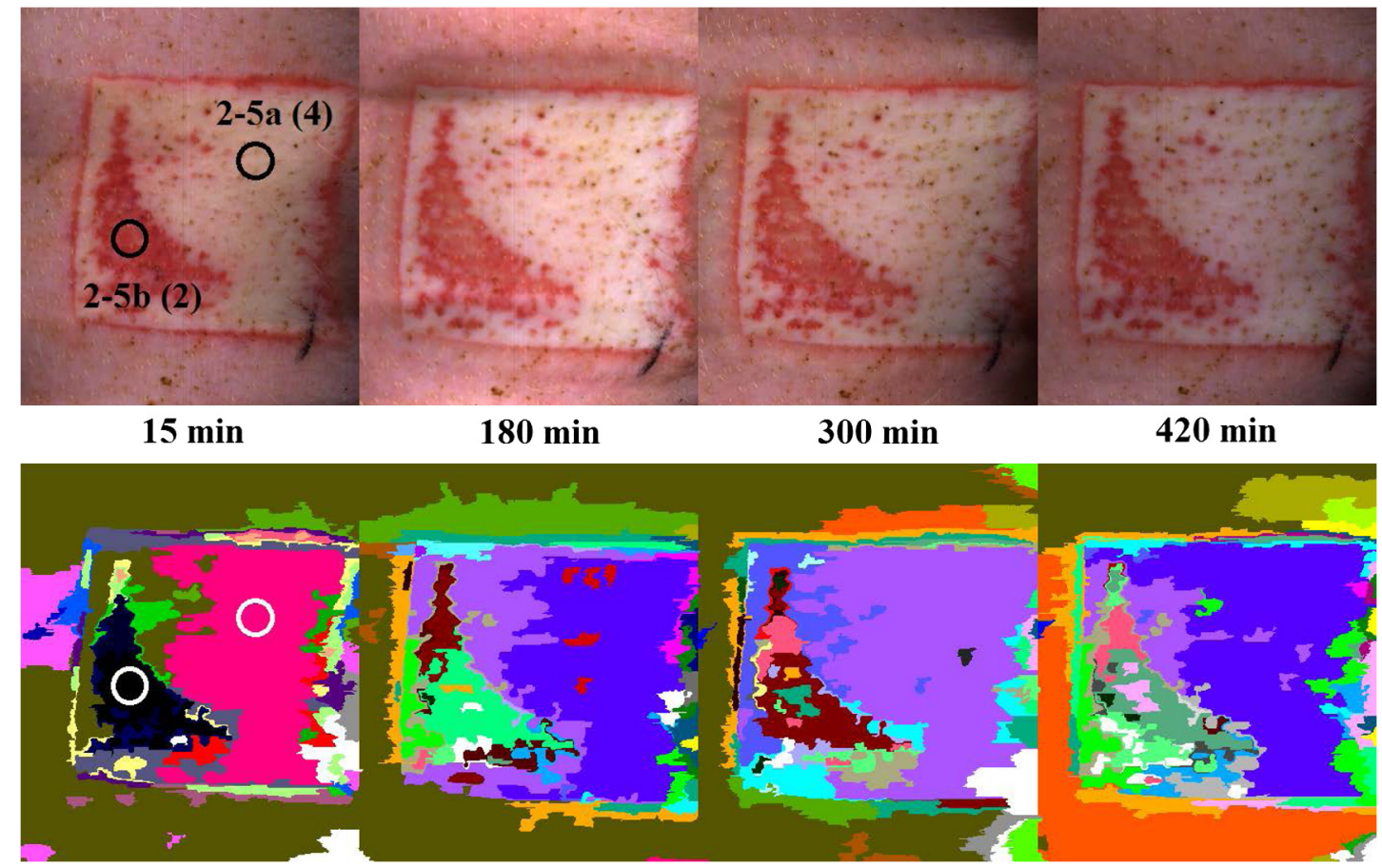

Fig. 9 Segmentation of 4-s burn over the course of $8 \mathrm{~h}$. Biopsy locations are marked with circles. Number in the brackets indicates the burn level. 


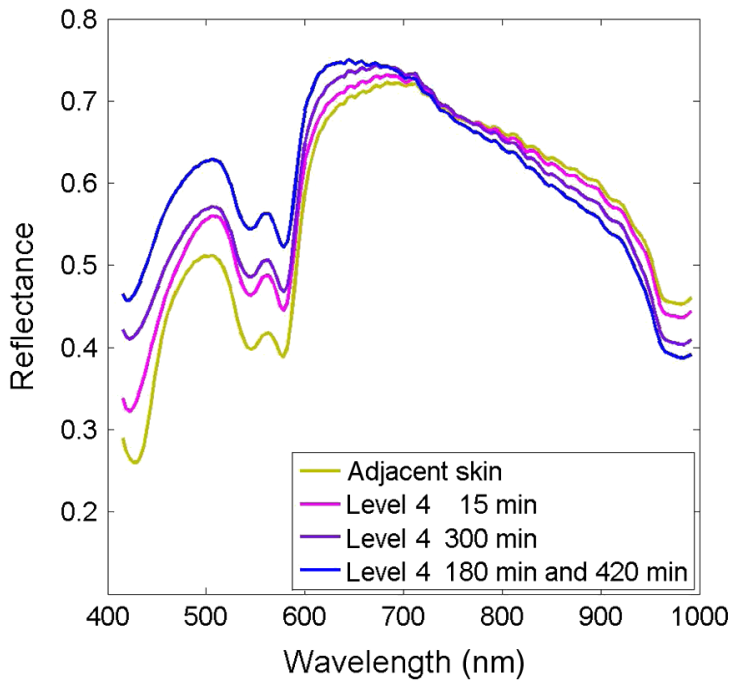

(a)

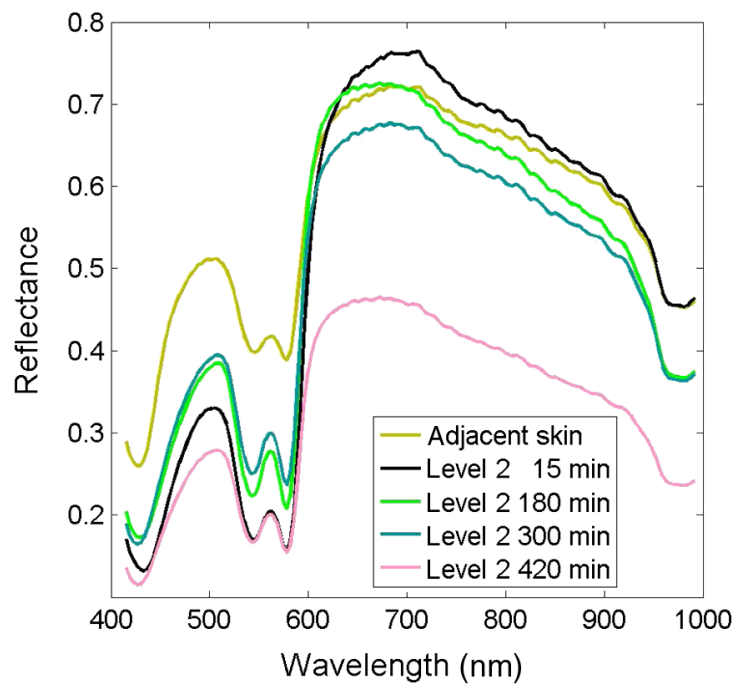

(b)

Fig. 10 Spectral profiles for (a) level 4 and (b) level 2 over the course of 8 h postburn.

with an inverse diffusion model previously described by Bjorgan et al. ${ }^{21}$ This will allow for real-time characterization of burn injuries in vivo.

\subsection{Burn Progression}

The proposed spectral-spatial algorithm was also used to track the postburn progression of the burn injuries over the course of $8 \mathrm{~h}$. This approach allows mapping of dynamic changes of the spectral properties within the burn wounds and surrounding tissue. Successive classification of the burn wound into the same cluster would indicate that the wound stabilized and the burn conversion stopped. Thus, tracking the wound dynamics can be used to identify the optimal time for diagnosis. Figure 9 shows stitched images of the same burn wound taken at four different times after burn introduction. Most of the surrounding skin has been classified as the same cluster, meaning the spectral characteristic of that region remained unchanged. Segmentation results indicate also that both levels 4 and 2 injuries undergo dynamic changes during $8 \mathrm{~h}$. Changes within level 4 burn can be mainly characterized as spectral variation, while spatial variation remains insignificant. The level 2 injury additionally to spectral changes exhibits spatial variation and the wound becomes more heterogeneous. Figure 10 shows corresponding spectral changes of the burn wounds. Visible differences in oxyand deoxyhemoglobin absorption peaks (in between 500 and $600 \mathrm{~nm}$ ) can be observed indicating changes in blood concentration and oxygenation. The level 4 injury exhibits decreased blood absorption as compared to the surrounding skin, unlike the level 2 that shows increased blood absorption. The decreasing reflectance at $970 \mathrm{~nm}$ indicates progressive increased water absorption for both injuries, to a larger extent in the level 2 burn than in the level 4 burn. Time-related changes of the burn wound were observed for all injuries included in this study. Future work will include data from additional animals collected over the course of $30 \mathrm{~h}$.

\section{Conclusions}

In this study, an animal experiment was designed and completed in order to test the performance of HSI on experimental burns.
Controlled burn wounds of graded severity were introduced, and hyperspectral images of the burn sites were used to implement an unsupervised segmentation algorithm. Histological evaluation of biopsy material confirmed that the clusters obtained using the implemented segmentation procedure represent burn wounds of varying severity. By analyzing hyperspectral images of the same burn site from different times, it was possible to track the wound dynamics. The study was performed in control environment and over limited postinjury time $(8 \mathrm{~h})$; however, we believe that spectral-spatial classification can be used for initial identification of burn wound of different severity. Future work will focus on using an inverse diffusion model for estimation of optical properties for clusters representing particular wound regions. This approach will allow initial differentiation of injuries and detailed characterization of parameters directly related to burn depth, e.g., dermal blood concentration and tissue scattering.

\section{Acknowledgments}

This study was partly financed by MEDIM-Norwegian Research School in Medical Imaging. The authors gratefully acknowledge Dr. Nils Kristian Skjærvold for the assistance with anesthesia of the pigs, and Tore Berg, and Tore Landsem from mechanical workshop for preparing the metal brass rod.

\section{References}

1. J. Converse, J. Platt, and D. Ballantyne, "An experimental evaluation of a histochemical diagnosis of burn depth," J. Surg. Res. 5(12), 547-551 (1965).

2. D. Heimbach et al., "Burn depth: a review," World J. Surg. 16, 10-15 (1992).

3. S. Monstrey et al., "Assessment of burn depth and burn wound healing potential," Burns 34, 761-769 (2008).

4. M. Kaiser et al., "Noninvasive assessment of burn wound severity using optical technology: a review of current and future modalities," Burns 37(3), 377-386 (2011).

5. M. D. Stern, "In vivo evaluation of microcirculation by coherent light scattering," Nature 254(5495), 56-58 (1975).

6. A. D. Jaskille et al., "Critical review of burn depth assessment techniques: part II. Review of laser Doppler technology," J. Burn Care Res. 31(1), 151-157 (2010). 
7. S. A. Pape, C. A. Skouras, and P. O. Byrne, "An audit of the use of laser Doppler imaging (LDI) in the assessment of burns of intermediate depth," Burns 27(3), 233-239 (2001).

8. H. Hoeksema et al., "Accuracy of early burn depth assessment by laser Doppler imaging on different days post burn," Burns 35(1), 36-45 (2009).

9. C. L. Riordan et al., "Noncontact laser Doppler imaging in burn depth analysis of the extremities," J. Burn Care Rehabil. 24(4), 177-186 (2003).

10. D. J. Cuccia et al., "Quantitation and mapping of tissue optical properties using modulated imaging," J. Biomed. Opt. 14(2), 024012 (2009).

11. J. Q. Nguyen et al., "Spatial frequency domain imaging of burn wounds in a preclinical model of graded burn severity," J. Biomed. Opt. 18(6), 066010 (2013).

12. A. Ponticorvo et al., "Quantitative assessment of graded burn wounds in a porcine model using spatial frequency domain imaging (SFDI) and laser speckle imaging (LSI)," Biomed. Opt. Express 5(10), 3467-3481 (2014).

13. B. S. Sorg, O. Donovan, and Y. Cao, "Hyperspectral imaging of hemoglobin saturation in tumor microvasculature and tumor hypoxia development," J. Biomed. Opt. 10(4), 044004 (2005).

14. M. E. Martin et al., "Development of an advanced hyperspectral imaging (HSI) system with applications for cancer detection," Ann. Biomed. Eng. 34(6), 1061-1068 (2006).

15. P. De Beule et al., "Rapid hyperspectral fluorescence lifetime imaging," Microsc. Res. Tech. 70(5), 481-484 (2007).

16. W. F. J. Vermaas et al., "In vivo hyperspectral confocal fluorescence imaging to determine pigment localization and distribution in cyanobacterial cells," Proc. Natl. Acad. Sci. U. S. A. 105(10), 4050-4055 (2008).

17. M. B. Sinclair et al., "Hyperspectral confocal microscope," Appl. Opt. 45(24), 6283-6291 (2006).

18. M. A. Calin et al., "Hyperspectral imaging in medical field: present and future," Appl. Spectrosc. Rev. 49(6), 435-447 (2014).

19. G. Lu and B. Fei, "Medical hyperspectral imaging: a review," J. Biomed. Opt. 19(1), 010901 (2014).

20. L. L. Randeberg et al., "Characterization of vascular structures and skin bruises using hyperspectral imaging, image analysis and diffusion theory," J. Biophoton. 3(1-2), 53-65 (2010).

21. A. Bjorgan, M. Milanic, and L. L. Randeberg, "Estimation of skin optical parameters for real-time hyperspectral imaging applications," J. Biomed. Opt. 19(6), 066003 (2014).

22. M. Denstedt et al., "Hyperspectral imaging as a diagnostic tool for chronic skin ulcers," Proc. SPIE 8565, 85650N (2013).
23. A. Bjorgan and L. L. Randeberg, "Real-time noise removal for linescanning hyperspectral devices using a minimum noise fraction-based approach," Sensors 15, 3362-3378 (2015).

24. A. Bjorgan and L. L. Randeberg, "Towards real-time medical diagnostics using hyperspectral imaging technology," Proc. SPIE 9537, 953712 (2015).

25. M.G. Sowa et al., "Near infrared spectroscopic assessment of hemodynamic changes in the early post-burn period," Burns 27(3), 241249 (2001).

26. K. M. Cross et al., "Near infrared point and imaging spectroscopy for burn depth assessment," Int. Congr. Ser. 1281, 137-142 (2005).

27. K. M. Cross, Assessment of Tissue Viability in Acute Thermal Injuries Using Near Infrared Point Spectroscopy, Institute of Medical Science, University of Toronto, Totonto (2010).

28. W. Eisenbeiss, J. Marotz, and J. P. Schrade, "Reflection-optical multispectral imaging method for objective determination of burn depth," Burns 25(8), 697-704 (1999).

29. M.A. Calin et al., "Characterization of burns using hyperspectral imaging technique-a preliminary study," Burns 41(1), 118-124 (2015).

30. A. Papp et al., "The progression of burn depth in experimental burns: a histological and methodological study," Burns 30(7), 684-690 (2004).

31. A. A. Green et al., "A transformation for ordering multispectral data in terms of image quality with implications for noise removal," IEEE Trans. Geosci. Remote Sens. 26(1), 65-74 (1988).

32. Y. Trabalka, J. A. Benediktsson, and J. Chanussot, "Spectral-spatial classification of hyperspectral imagery based on partitional clustering techniques," IEEE Trans. Geosci. Remote Sens. 47(8), 2973-2987 (2009).

33. F. A. Kruse et al., "The spectral image processing system (SIPS) - interactive visualization and analysis of imaging spectrometer data," Remote Sens. Environ. 44(1), 145-163 (1993).

34. J. A. Benediktsson and P. Ghamisi, Spectral-Spatial Classification of Hyperspectral Remote Sensing Images, Artech House, London (2015).

35. C. Gaines et al., "Development of a porcine deep partial thickness burn model," Burns 39(2), 311-319 (2013).

36. L. O. Svaasand et al., "Tissue parameters determining the visual appearance of normal skin and port-wine stains," Laser Med. Sci. 10(1), 55-65 (1995).

Biographies for the authors are not available. 